\title{
Adverse Effects Profile of Dicycloplatin (DCP) Offers Chemotherapeutic Advantage Over Cisplatin and Carboplatin
}

\author{
JING JIE YU ${ }^{1}$, THOMAS HOGAN ${ }^{2}$, CHAD MORLEY $^{3}$, CHAD CRIGGER $^{3}$, SHUNCHANG JIAO $^{4}$, \\ DORIAN J. WILLIAMS ${ }^{5}$, MOHAMAD W. SALKINI ${ }^{3}$, XUQING YANG ${ }^{6}$, XIAOBING LIANG $^{1}$, BINGXUE YAN ${ }^{1}$, \\ COURTNEY CECIL ${ }^{7}$, AVA C. WINN ${ }^{8}$, JENNY ZHENG ${ }^{1}$, YI GUO ${ }^{1}$, BING-HUA JIANG ${ }^{9}$ and IDA M. WASHINGTON ${ }^{7}$ \\ ${ }^{1}$ Department of Biochemistry, School of Medicine, School of Pharmacy, WVU Cancer Institute, Morgantown, WV, U.S.A.; \\ ${ }^{2}$ Department of Medicine, School of Medicine, West Virginia University, Morgantown, WV, U.S.A.; \\ ${ }^{3}$ Department of Urology, School of Medicine, West Virginia University, Morgantown, WV, U.S.A.; \\ ${ }^{4}$ Oncology Department of Internal Medicine, PLA General Hospital, Beijing, P.R. China; \\ ${ }^{5}$ Department of Family Medicine, School of Medicine, West Virginia University, Morgantown, WV, U.S.A.; \\ ${ }^{6}$ Department of Chemistry, Peking University and Beijing Xingda Scientific System Company, Beijing, P.R. China; \\ ${ }^{7}$ Office of Laboratory Animal Resources, West Virginia University, Morgantown, WV, U.S.A.; \\ ${ }^{8}$ Molecular Biology Core Facility, National Institute for Occupational Safety and Health, CDC, Morgantown, WV, U.S.A.; \\ ${ }^{9}$ Department of Pathology, Carver College of Medicine, University of Iowa, Iowa City, IA, U.S.A.
}

\begin{abstract}
Background/Aim: Platinum-based chemotherapy often fails due to its severe adverse effects. The aim of this study was to examine the adverse effects profile and efficacy of dicycloplatin and compare them to those of cisplatin and carboplatin. Materials and Methods: Cystoscopy surveillance of the first American cancer patient treated with dicycloplatin was performed quarterly. In vitro and in vivo studies were conducted using immunoblotting and flow cytometry to assess immune status of spleen and bone marrow of mice treated with dicycloplatin, cisplatin and carboplatin. Results: The American patient did not suffer clinically significant myelosuppression; dicycloplatin has sustained remission in this patient to date. Experimental studies showed that dicycloplatin is less toxic to bone marrow and spleen of mice than cisplatin and carboplatin. Conclusion: Dicycloplatin is a promising drug in cancer chemotherapy with less aggressive side-effects than those typically associated with cisplatin and carboplatin. This is an important therapeutic advantage in cancer chemotherapy. Clinical investigation of dicycloplatin as an alternative to cisplatin or carboplatin is warranted.
\end{abstract}

This article is freely accessible online.

Correspondence to: Jing Jie Yu, MD, WVU Cancer Institute, P.O. Box 9300, Morgantown, WV 26506 U.S.A. Tel: +1 3042938661, Fax: +1 3042934667, e-mail: jyu@hsc.wvu.edu; yujingjie@hotmail.com

Key Words: Chemotherapy, dicycloplatin (DCP), tolerable side effects, therapeutic advance.
Platinum-based chemotherapy, primarily cisplatin and carboplatin, has been a front-line therapy for many years. The major international guidelines recommend platinumbased chemotherapy as the standard first-line therapy for various cancers. In general, cisplatin and carboplatin have similar mechanisms of action; they are cytotoxic drugs that kill cancer cells by damaging DNA, inhibiting DNA synthesis and mitosis, and leading to apoptotic cell death (1$5)$. However, their adverse effects are often severe, leading to treatment failure.

Cisplatin, cis-diamminedichloroplatinum(II), is a platinum coordination compound whose anticancer effects were discovered in 1965 by Barnett Rosenberg of Michigan State University. Rosenberg found that electrolysis of platinum electrodes generated a soluble platinum complex which inhibited cell division in $E$. coli bacteria. This finding led to the observation that cisplatin was highly effective at regressing sarcomas in rats. In 1978, cisplatin was the first platinum compound approved by the Food and drug Administration (FDA) of the United States of America for cancer treatment. Cisplatin is one of the most effective anticancer agents and has been widely used in the treatment of malignancies, including head and neck, lung, ovarian, blood, breast, brain, kidney and testicular cancers (6).

Carboplatin or cis diammine (1,1-cyclobutanecarboxylato) platinum (II), the second-generation of platinum drugs, was discovered at the Institute of Cancer Research and the Royal Marsden Hospital in London. Carboplatin was approved by the USA FDA in 1989. Compared to cisplatin, the greatest benefit of carboplatin is its reduced side effects, particularly less nephrotoxicity. Carboplatin 
shows a significantly lower excretion rate, hence its effects are longer lasting (a retention half-life of $30 \mathrm{~h}$ for carboplatin, compared to 1.5-3.6 h for cisplatin). However, carboplatin is myelosuppressive, causing dramatic decrease in blood cells and platelets (7).

Thus, the main drawbacks of current platinum anticancer drugs are their substantial side effects, including hepatotoxicity, nephrotoxicity, bone marrow suppression, neurotoxicity, severe nausea/vomiting and hair loss, and ototoxicity (in children). Cisplatin and carboplatin show different toxicity profiles; cisplatin is associated more with gastrointestinal (GI) adverse effects, neurotoxicity, and renal/kidney problems, whereas carboplatin is more associated with myelosuppression (5). The adverse effects of cisplatin and carboplatin are often severe, causing some patients to stop treatment.

Dicycloplatin (DCP), cis-diammine (1,1-cyclobutanedicarboxylate) platinum (II), 1,1-cyclobutancdicarboxylic acid complex is a newcomer in platinum-based chemotherapy. DCP's molecular weight is 515.39 ; its solubility in water is $4 \mathrm{~g} / 100 \mathrm{ml}$, compared to $1.5 \mathrm{~g} / 100 \mathrm{ml}$ for carboplatin and $0.2 \mathrm{~g} / 100 \mathrm{ml}$ for cisplatin. DCP was developed in China and approved by the China's FDA in March of 2012. This compound has a stable chemical structure, good water solubility, and an excellent safety profile $(8,9)$.

Preclinical in vitro and in vivo DCP studies and a phase I clinical trial in China found greater antitumor activity and fewer adverse events than carboplatin $(8,9)$. A doubleblind, randomized multicenter Phase II clinical trial comparing DCP-plus-paclitaxel to carboplatin-pluspaclitaxel in 240 patients with advanced non-small cell lung cancer found efficacy and safety of DCP-pluspaclitaxel comparable to carboplatin-plus-paclitaxel, but with better drug tolerability $(8,9)$.

\section{The First American Cancer Patient to Receive Dicycloplatin Chemotherapy}

In 2016, an American cancer patient received 8 weeks of DCP chemotherapy (via IV, $300 \mathrm{mg} /$ week) in Beijing following diagnosis of bladder carcinoma and tumor resection at West Virginia University (WVU) Hospital.

The 65-year-old Caucasian male presented with increasing hematuria over four months; consent forms were signed and clinical work-up and scans revealed a $1.5 \mathrm{~cm}$ bladder mass, with a subsequent pathologic diagnosis of non-invasive highgrade papillary urothelial carcinoma. The patient declined Bacillus Calmette-Guérin (BCG) immunotherapy and traveled to China for DCP chemotherapy. Consent forms were signed and he received 8 weeks of IV DCP (300 mg/week), followed by quarterly surveillance at WVU Hospital. The patient has received DCP only, with no evidence to date of tumor recurrence. The patient experienced tolerable side effects during DCP chemotherapy (10-12).
In this report, we update the surveillance observations of the first American patient receiving DCP therapy and provide case-relevant in vitro and in vivo DCP studies by researchers at WVU and colleagues at other institutions. The in vivo study examined the side effects of DCP, cisplatin and carboplatin in organs of mice, which reflect impact on their hematologic and immune systems.

\section{Materials and Methods}

Drugs. Cisplatin (P-4394-1G, Sigma-Aldrich, St. Louis, MO, USA), carboplatin (NIH, RPT RFG 7/9/99 241240-2/22/10GM) and DCP ( $>99.0 \%$ purity; Beijing Xing-Da Medicine Co., Ltd, China) were used at $1 / 2$ of $\mathrm{LD}_{50}$ (the amount of an agent sufficient to kill 50 percent of a treated population of animals) dosages for in vivo studies: cisplatin (3.3 $\mathrm{mg} / \mathrm{kg})$, carboplatin $(59 \mathrm{mg} / \mathrm{kg})$ and DCP $(105 \mathrm{mg} / \mathrm{kg})$. Each drug was freshly prepared by dissolving in water to achieve $0.275 \mathrm{mg} / \mathrm{ml}$ for cisplatin, $4.917 \mathrm{mg} / \mathrm{ml}$ for carboplatin and $8.75 \mathrm{mg} / \mathrm{ml}$ for DCP.

In vitro cell culture and DCP treatment. Human ovarian normal IOSE364 and cancer A2780 cells, and prostate normal RWPE-2 and cancer DU145 cells were propagated as adherent monolayers in RPMI-1640 medium supplemented with $10 \%$ heat-inactivated fetal bovine serum (FBS), $100 \mu \mathrm{g} / \mathrm{ml}$ penicillin and $100 \mu \mathrm{g} / \mathrm{ml}$ streptomycin (Life Technologies, Grand Island, NY, USA). Cells were grown at $37^{\circ} \mathrm{C}$ in a humidified atmosphere consisting of $5 \% \mathrm{CO} 2$, $95 \%$ air and allowed to grow to $80 \%$ confluence. For drug treatment experiments, cells were plated the day before exposure to drugs.

DCP was prepared at $\mathrm{IC}_{50}$ doses $(3.79 \mu \mathrm{M})$ by first dissolving it in water and then diluting it in pre-warmed media to achieve the concentration of $500 \mathrm{mg} / \mathrm{ml}$. Plated cells were allowed to grow for 24-h and treated with DCP for $1 \mathrm{~h}$. At the end of $1 \mathrm{~h}$ exposure to drug, cells were washed twice with PBS, and further incubated with drug-free media for the required period of time.

Protein extraction and immunoblotting. Treated and untreated cells were extracted with whole cell lysis buffer [20 mM Tris-HCl (pH 7.5), $150 \mathrm{mM} \mathrm{NaCl}, 1 \mathrm{mM} \mathrm{Na} 2$ EDTA, $1 \mathrm{mM}$ EGTA, $1 \%$ Triton, $2.5 \mathrm{mM}$ sodium pyrophosphate, $\beta$-glycerophosphate, $1 \mathrm{mM} \mathrm{Na} \mathrm{VO}_{4}, 1 \mathrm{mM}$ phenylmethylsulfonyl fluoride (PMSF), $10 \mu \mathrm{g} / \mathrm{ml}$ leupeptin, $10 \mu \mathrm{g} / \mathrm{ml}$ aprotinin and $5 \mu \mathrm{g} / \mathrm{ml}$ pepstatin] for $30 \mathrm{~min}$ before centrifugation (at $16,000 \times g$ for $30 \mathrm{~min}$ at $4^{\circ} \mathrm{C}$ ). Supernatant was collected as whole-cell lysate for western blot analysis. Protein concentration of extracts was determined by Bio-Rad Protein Assay kit (Bio-Rad, Hercules, CA, USA) with bovine serum albumin as standard. The whole-cell lysates were separated on $12 \%$ sodium dodecyl sulfate (SDS)-polyacrylamide gels and transferred to PVDF (polyvinyl difluoride) membrane (BioRad) using standard electrophoresis and electroblotting procedures. Prestained molecular weight markers were purchased from Invitrogen (Carlsbad, CA, USA). To reduce non-specific binding, blots were preincubated for 1-h in a blocking buffer (5\% nonfat dry milk, $1 \times \mathrm{TBS}$ and $0.1 \%$ Tween 20). Membranes were then incubated with primary antibodies overnight at $4^{\circ} \mathrm{C}$. The primary antibodies for DNA damage pathway applied were against p53 phosphoserine-15, p53, CHK2 phosphothreonine-68, CHK2, BRCA1 phosphoserine-1497, BRCA1, and $\mathrm{p} 21$; and for apoptosis pathway were against p53, p-Chk1, $\beta$-Bax, $\alpha$-Bax, Caspase- 3 , Cleaved-Caspase- 3 and Parp. To demonstrate equal loading of each sample, membranes were re-probed using an antibody to $\beta$-actin (Sigma-Aldrich Corp. St. Louis, MO, USA). The signals of 
A

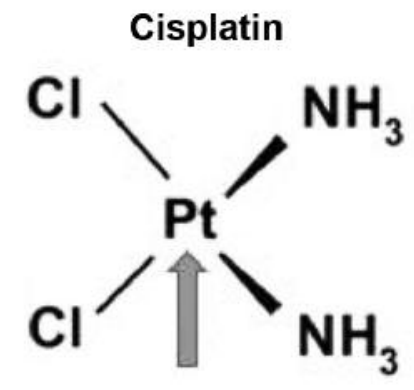

US FDA approval: 1978
B<smiles>CCCC1(CC)C(=O)O[P+](C)(N)OC1=O</smiles>

US FDA approval: 1989

\section{C}

\section{Dicycloplatin}

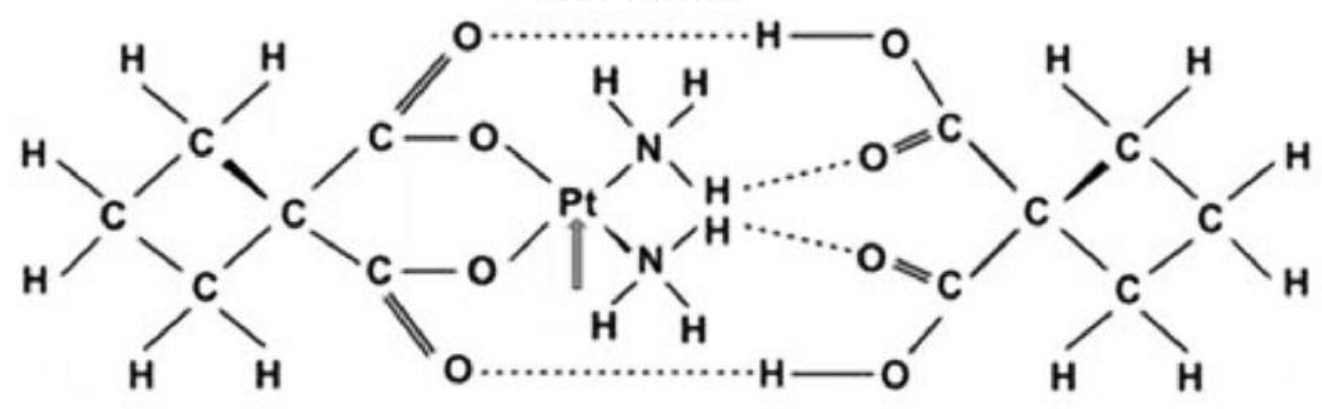

China FDA approval: 2012

Figure 1. Chemical structure of cisplatin, carboplatin and dicycloplatin. Cisplatin, carboplatin and dicycloplatin are all composed of a platinum ion, amine ligands and a leaving group (a molecular fragment that departs with a pair of electrons in heterolytic bond cleavage), which allows the platinum ion to form bonds with DNA bases. Unlike cisplatin and carboplatin (Figure 1A and B), which are covalent-bond molecules, dicycloplatin is a supramolecule composed of two molecules: carboplatin (host) and 1,1-cyclobutane dicarboxylate ligand (guest) interconnected via four hydrogen bonds (dotted lines in Figure 1C).

immunoreactive proteins were visualized using horseradish peroxidaseconjugated sheep anti-mouse or donkey anti-rabbit antibodies and enhanced Chemiluminescence ECL detection system (Amersham International PLC, Buckinghamshire, UK).

Animals. Animal studies were approved by the WVU Institutional Animal Care and Use Committee. Swiss Webster mice (Taconic) were housed at 1-5 per individually ventilated cage on corncob bedding and maintained under a 12-h light/12-h dark cycle, at temperature and humidity parameters consistent with recommendations of the Guide for the Care and Use of Laboratory Animals (https://www.aaalac.org/ resources/theguide.cfm). For experiments, male and female mice were used between 2-7 months of age.

Experiment/Treatments. For in vivo studies, mice were administered by intraperitoneal injection a single non-lethal dose of cisplatin (3.3 $\mathrm{mg} / \mathrm{kg} ; \mathrm{n}=6)$, carboplatin $(59 \mathrm{mg} / \mathrm{kg} ; \mathrm{n}=7)$, DCP $(105 \mathrm{mg} / \mathrm{kg} ; \mathrm{n}=7)$ or vehicle control (water; $n=7$ ). Mice were weighed and visually assessed pre- and post-treatment at $24 \mathrm{~h}, 48 \mathrm{~h}, 72 \mathrm{~h}$, and $7 \mathrm{~d}$. At the end of the study, mice were bled via the facial vein and then euthanized with isoflurane overdose and decapitated. Organs/tissues (at $24 \mathrm{~h}, 48 \mathrm{~h}, 72 \mathrm{~h}$, and $7 \mathrm{~d}$ post-treatment) were harvested and flash-frozen in liquid nitrogen.
Flow cytometry. Single cell suspensions were generated by mechanical dissociation and filtering through $70 \mu \mathrm{m}$ nylon mesh. Red blood cells were removed by ACK (Ammonium-ChloridePotassium) lysis. Cells were prepared in FACS buffer and $\mathrm{Fc}$ blocked (clone 2.4G2, BD Biosciences). Cocktails of mAbs from BD Biosciences were added for $30 \mathrm{~min}$ at $4^{\circ} \mathrm{C}$. Dead cells were excluded using a Live-dead fixable dye (Invitrogen ${ }^{\mathrm{TM}}$ ). For the detection of cell-cycle progression, cells were fixed in $70 \%$ ethanol, followed by RNase A treatment and propidium iodide (PI) staining. Apoptotic cells were detected using Dead Cell Apoptosis Kit with Annexin V Alexa Fluor ${ }^{\mathrm{TM}} 488$ \& PI (Invitrogen ${ }^{\mathrm{TM}}$ ) according to the manufacturer's instructions. Samples were acquired on a BD Fortessa using BD FACSDiva software (BD Bioscience) and postacquisition analysis performed using FCS Express 6 software (De Novo Software).

\section{Results}

Chemical structure and physicochemical properties of cisplatin, carboplatin and dicycloplatin. Cisplatin and carboplatin are composed of a doubly-charged platinum ion surrounded by four ligands. The amine ligands form strong 
Table I. Common adverse effects (AE) of cisplatin and carboplatin vs. dicycloplatin (DCP) experience of American cancer patient.

\begin{tabular}{lc}
\hline $\begin{array}{l}\text { Reported cisplatin/ } \\
\text { carboplatin AE }\end{array}$ & $\begin{array}{r}\text { DCP CTCAE* grade of } \\
\text { American patient }\end{array}$ \\
\hline Leucopenia & 0 \\
Neutropenia & 0 \\
Anemia & 0 \\
Thrombocytopenia & 0 \\
Hair Loss & 0 \\
Nausea & 1 \\
Vomiting & 0 \\
Stomatitis & 0 \\
Diarrhea & 0 \\
Constipation & 0 \\
Neurotoxicity & 0 \\
Renal toxicity & 0
\end{tabular}

*NCI Common Terminology Criteria for Adverse Events (Grade 1-5).

interactions with the platinum ion; the two chloride ligands in cisplatin or the bidentate dicarboxylate (CBDCA) ligand in carboplatin create a leaving group (a molecular fragment that departs with a pair of electrons in heterolytic bond cleavage) which allows the platinum ion to form bonds with DNA bases (Figure 1A and B).

DCP is synthesized from platinum powder through a 10-step process. X-ray single crystal diffraction shows that the end product of DCP is a supramolecule composed of two molecules: carboplatin (host) and 1,1-cyclobutane dicarbo-xylate ligand (guest) interconnected via four hydrogen bonds (dotted lines in Figure 1C). Unlike carboplatin, a covalent-bond molecule, DCP is a hydrogen bond supramolecule.

To determine if DCP is not hydrolyzed to carboplatin inside the body - that the effect-driving substance is DCP, not carboplatin - prototype concentration of DCP in patient blood samples after DCP administration was measured using AB$4000^{\mathrm{TM}}$ LC-MS/MS instrumentation, with carboplatin plasma concentration as comparison. The results demonstrated that the spectrum-profiles of DCP and carboplatin are different; the majority of DCP is still present as prototype DCP in plasma 2 $h$ after administration $(8,9)$.

Common platinum drug adverse effects vs. DCP side effects experienced by the American cancer patient. A 65-year-old Caucasian American male with increasing hematuria over a 4-month period was seen at WVU Hospital, Morgantown, WV, USA. The patient had a Transurethral Resection of Bladder Tumor (TURBT) showing high-grade urothelial carcinoma (TCC: Transitional Cell Bladder Cancer) of intermediate risk, with an enlarged prostate, and lower urinary tract symptoms (LUTS). Resection was performed on June 30, 2016. In July 2016, the patient traveled to
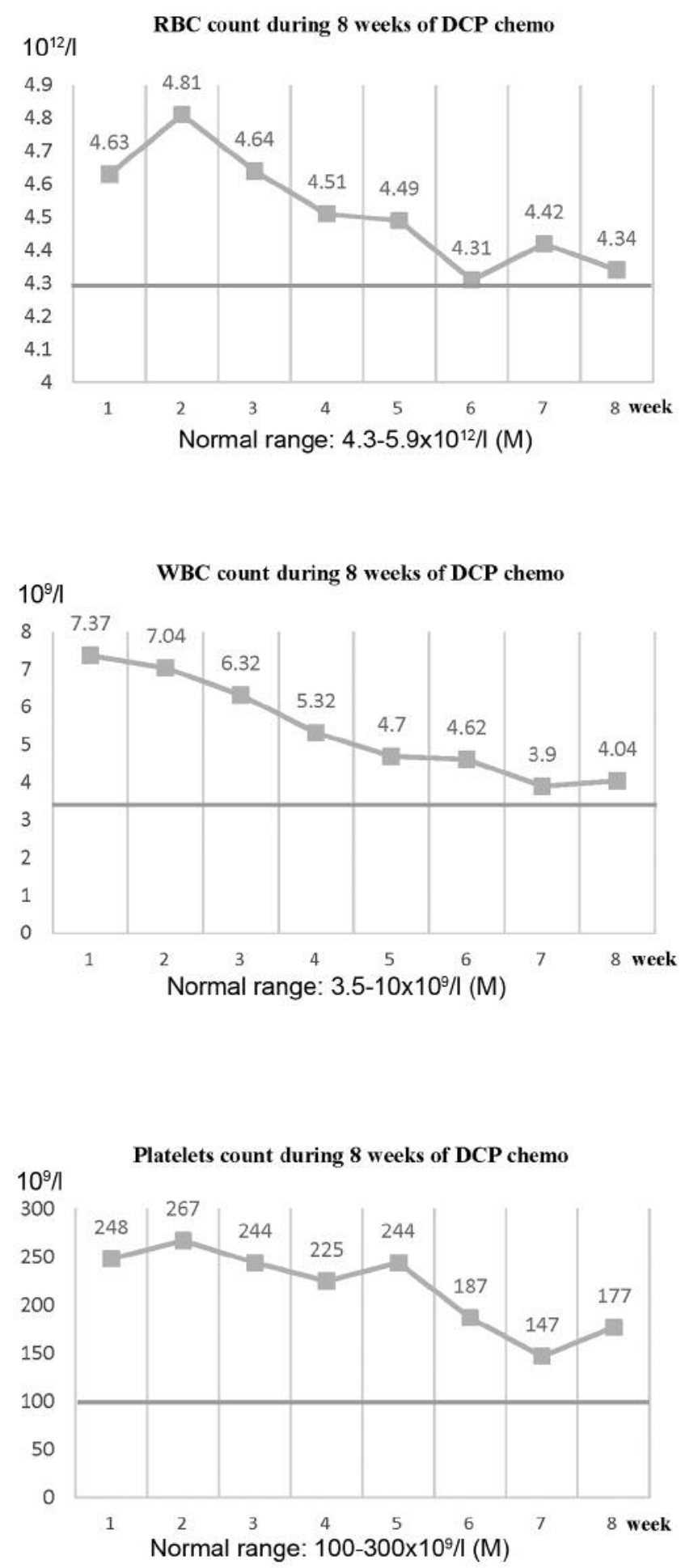

Figure 2. Hematologic data - complete blood count (CBC) with differential during DCP chemotherapy of the American cancer patient. Baseline blood counts and chemistry were evaluated prior to chemotherapy, then weekly before each treatment. Figure 2 shows the weekly hematologic monitoring of the American cancer patient. Red blood cells, white blood cells and platelets decreased, but all remained within normal limits. 
Yu et al: DCP Offers Chemotherapeutic Advantage Over Cisplatin and Carboplatin

Table II. Complete blood count (CBC) with differential, July-September 2016, Beijing 301 Hospital, China

\begin{tabular}{lcccccccccc}
\hline & & \multicolumn{3}{c}{ Pre-DCP } & \multicolumn{5}{c}{ DCP Treatment } \\
\cline { 6 - 10 } & Reference range & Unit & $7 / 20 / 2016$ & $7 / 26 / 2016$ & $8 / 2 / 2016$ & $8 / 9 / 2016$ & $8 / 16 / 2016$ & $8 / 23 / 2016$ & $8 / 30 / 2016$ & $9 / 6 / 2016$ \\
\hline RBC & $4.3-5.9(\mathrm{M}) ; 3.9 \sim 5.2(\mathrm{~F})$ & $10^{12} / 1$ & 4.63 & 4.81 & 4.64 & 4.51 & 4.49 & 4.31 & 4.42 & 4.34 \\
WBC & $3.5 \sim 10$ & $109 / 1$ & 7.37 & 7.04 & 6.32 & 5.32 & 4.7 & 4.62 & 3.9 & 4.04 \\
Platelets & $100 \sim 300$ & $109 / 1$ & 248 & 267 & 244 & 225 & 244 & 187 & 147 & 177 \\
\hline
\end{tabular}

Beijing, where he received eight weekly DCP IV treatments (300 mg/week) (10).

Baseline blood counts and chemistry were evaluated prior to chemotherapy, then weekly before each treatment. As shown in Table I, the American cancer patient experienced minor/slight adverse effects, including mild nausea, moderate fatigue and, during the last weeks, back and leg aches. However, there was no vomiting or hair loss. Weekly hematologic monitoring showed a decrease in red blood cells, white blood cells and platelets, but all remained within normal limits (Table II and Figure 2). The suppressive effects of DCP on bone marrow were not clinically significant. In other words, his immune system remained largely intact.

DCP chemotherapy clinical results: cystoscopy images of bladder tumor and resection site of American patient. After completion of DCP chemotherapy, the patient returned to the United States for quarterly cystoscopy follow-up at WVU Hospital. Cystoscopies performed on October 13, 2016, January 16, 2017, April 20, 2017, August 3, 2017 and April 24, 2018 revealed no recurrence of tumor. In Figure 3, images taken during cystoscopy before tumor resection (Figure 3A) and after resection (Figure 3B) on June 30, 2016. The 1-year follow-up image is shown in Figure 3C. The resection site was observed to be clear of new growth on each occasion. Wash solutions collected during each cystoscopy were examined by a Cytologist and no malignant cells were observed on each follow-up (10-12).

On December 6, 2018, a contrast CT-IVP found that the bladder wall had no thickening or nodularity. A follow-up cysto-urethroscopy with bladder barbotage four days later showed no evident tumor recurrence at the resection site (Figure 3, bottom panels D, E and F). Bladder wash cytology was negative for malignant cells. Physical examination by the urologic surgeon at time of cystoscopy was unremarkable.

In vitro molecular studies of DCP-activated signaling pathways in normal and cancer cells. DCP-induced DNA damage in human ovarian normal IOSE364 and cancer A2780 cells was investigated at the WVU Molecular Medicine Core Facility to determine the DCP-activated signaling pathways. After 1 -h drug exposure at $\mathrm{IC}_{50}$ doses
(3.79 $\mu \mathrm{M})$, several kinases of the DNA-damage/repair pathway were activated. Activated kinases, including p-p53, p-Chk2 and p-BRCA1, were observed in cancer cells but not normal cells (Figure 4, left panels).

DCP-activated apoptosis pathway in human prostate normal RWPE-2 and cancer DU145 cells was also investigated. Cells were exposed to different concentrations of DCP for 1-h and cultured in drug-free media for 24-h. Western blot analysis showed that DCP activated several crucial genes, including p53, Bax and Caspase-3, in the apoptosis pathway in cancer cells but not in normal cells (Figure 4, right panels).

These data suggest the possibility that DCP mainly affects tumor cells. Further investigation might indicate the molecular basis of DCP's more tolerable side-effects.

In vivo studies on the adverse effects of DCP, cisplatin and carboplatin on spleen and bone marrow of normal mice - an immunological assessment. Swiss Webster mice were treated with cisplatin (CDDP), carboplatin (Carbo), or dicycloplatin (DCP) at $1 / 2 \mathrm{LD}_{50}$ (half of the dose that kills $50 \%$ of animals) doses, intraperitoneal injections for 7 days. Eightcolor flow cytometry was carried out to evaluate the effects of the three platinum drugs on bone marrow, cell-cycle arrest and immune status of the spleen.

Figure 5 shows cisplatin induced more apoptosis, including both early and late apoptosis, in bone marrow than DCP, indicating that DCP is less toxic to bone marrow than cisplatin. Cisplatin and carboplatin arrested more splenocytes in the $\mathrm{G}_{1}$ phase of cell cycle $(74.1 \%$ and $53.6 \%$ ), compared to DCP (44\%), suggesting that DCP causes less damage to spleen cells than cisplatin and carboplatin (Figure 6). Furthermore, DCP showed less suppression of CD8 T cells and CD8 memory $\mathrm{T}$ cells than cisplatin. DCP-treated mice also retained more CD4 memory $\mathrm{T}$ cells, compared to mice treated with cisplatin or carboplatin, suggesting that the immune status of mice treated with DCP is less compromised than those treated with cisplatin or carboplatin (Figure 7). Of note, CD8+ T cells, CD8+ memory $\mathrm{T}$ cells and CD4+ memory $\mathrm{T}$ cells play key role in immune system status (13-15).

Our in vivo immunological findings are consistent with clinical observations that DCP shows more tolerable side effects than those typically associated with cisplatin and carboplatin. 

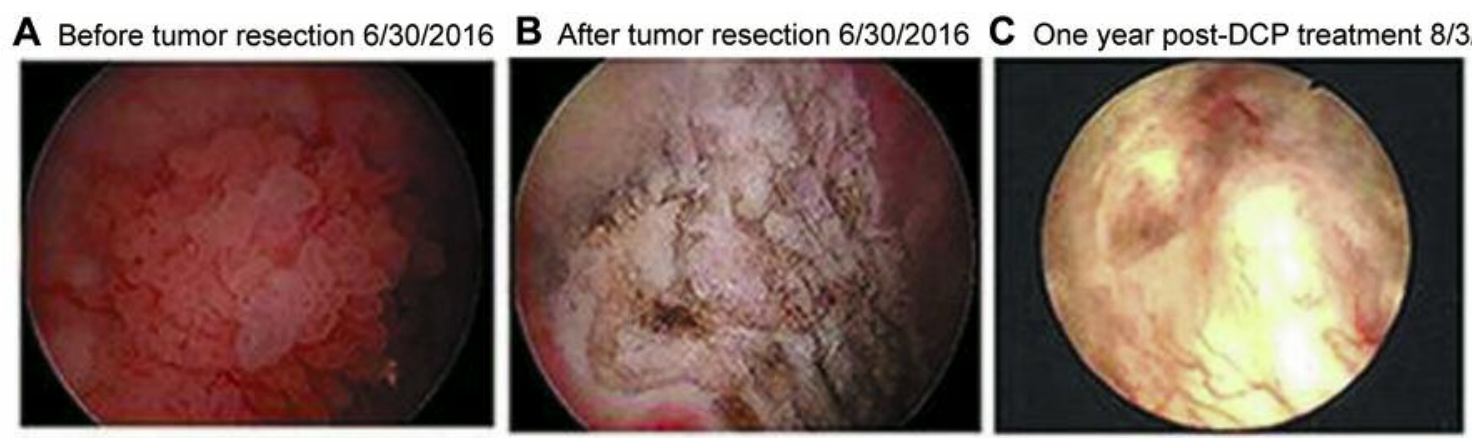

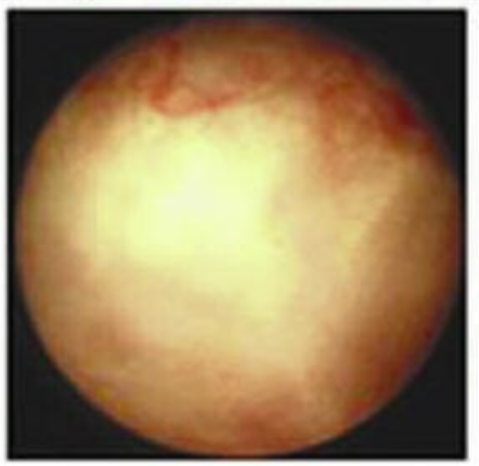

D Previous scar

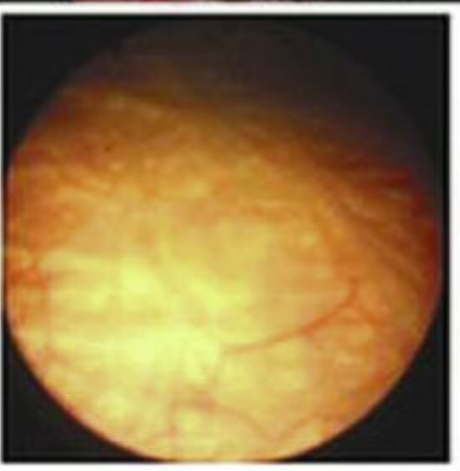

E Normal-appearing posterior wall

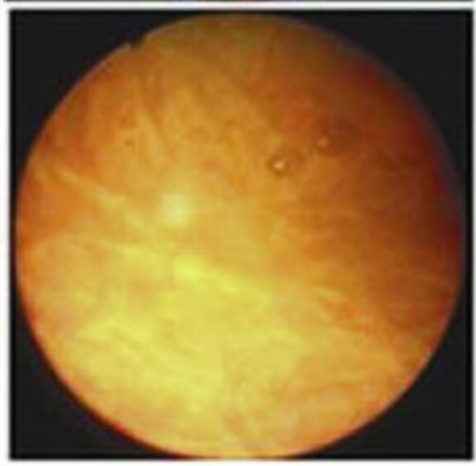

F Normal-appearing dome

(D-F, 27 months post-DCP treatment 12/10/2018)

Figure 3. Cystoscopy images of bladder tumor and resection site. Quarterly cystoscopy follow-up on all occasions revealed no recurrence of tumor, and the resection area was observed to be clear of new growth. The images taken during cystoscopy before (A) and after (B) tumor resection on June 30, 2016; the residue of the tumor lesion during 1-year follow-up (C); and, images during follow-up on Dec 10, 2018 (D, E and F).

DCP-Induced DNA Damage Response in Ovarian Normal and Cancer Cells
DCP-Induced Apoptosis Pathway in Prostate Normal and Cancer Cells

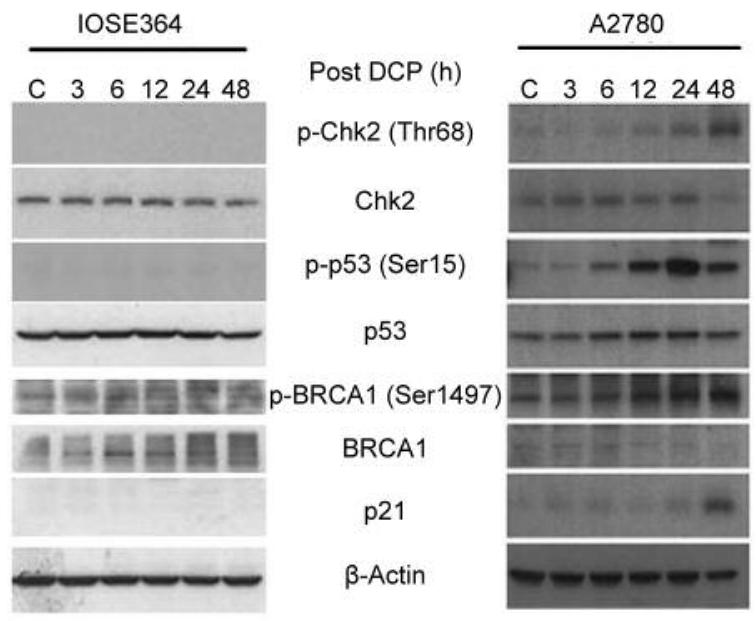

RWPE-2

$$
\text { C } 2550100200 \mathrm{DCP}(\mathrm{nM})
$$
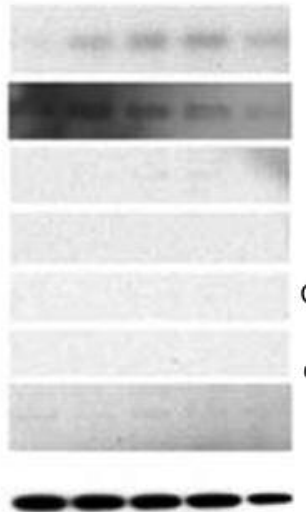

\section{p53 \\ p-Chk1 \\ $\beta$-Bax \\ $\alpha-B a x$ \\ Caspase-3 \\ Cleaved- caspase-3 \\ Parp \\ $\beta$-Actin}

DU145

C $\quad 25 \quad 50 \quad 100 \quad 200$
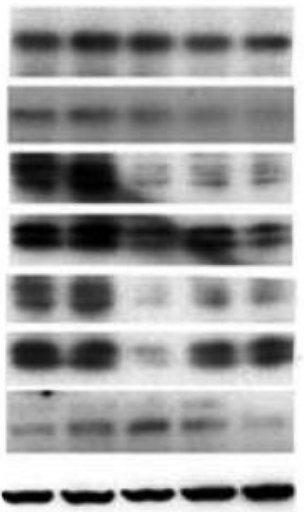

Figure 4. In vitro studies of the molecular mechanism of DCP-activated signaling pathways in normal and cancer cells. DCP was prepared to achieve the required concentrations. Normal ovarian IOSE364 and cancer A2780 cells were treated with DCP and the levels of markers of DNA damage-repair pathways were examined by western blot. Normal prostate RWPE-2 and cancer DU145 cells were treated with different concentrations of DCP and the levels of markers of apoptosis were determined by western blot. Cells were allowed to grow for $24 \mathrm{~h}$, treated with $D C P$ for $1 \mathrm{~h}$, washed twice with PBS, and then incubated with drug-free media for the indicated periods of time. Treated and untreated cells were lysed with whole-cell lysis buffer for western blot analysis. Proteins on membranes were incubated with primary antibodies overnight at $4^{\circ} \mathrm{C}$. The signals of immunoreactive proteins were visualized. 


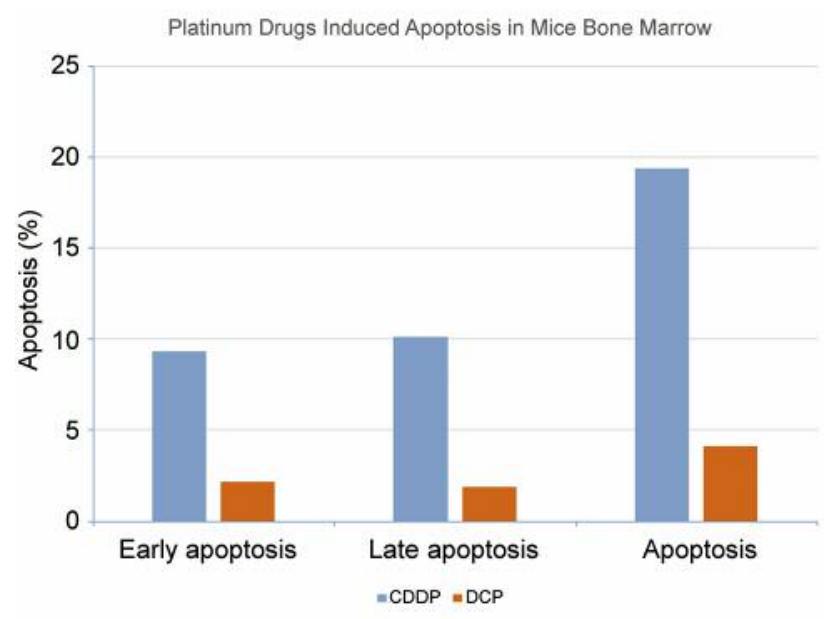

Figure 5. Cisplatin and dicycloplatin induced apoptosis in bone marrow of mice. Swiss Webster mice were intraperitoneally injected for 7 days with cisplatin $(C D D P)$ and dicycloplatin $(D C P)$ at $1 / 2 L D_{50}$ doses. Flow Cytometry analysis was carried out to evaluate the effects of the two platinum drugs on bone marrow.

\section{Discussion}

Platinum compounds such as cisplatin and carboplatin are the most effective and widely used anticancer agents employed in the treatment of solid tumors. Platinum drugs have been extensively used for the treatment of ovarian, lung, blood, breast, brain, kidney, head and neck, and testicular cancers (5). However, platinum chemotherapy often has severe side effects. Some patients relapse and become refractory to platinum drugs; some stop treatment. Combination therapies of platinum compounds and other drugs are common practice in the attempt to overcome drug resistance and reduce undesirable side-effects $(3,4)$.

The DCP experience of an American bladder cancer patient - carefully documented in the United States and in China - is very much the same as observed among Chinese cancer patients $(8,9)$. DCP has sustained remission in the American patient for nearly 3 years. Furthermore, his DCP chemotherapy experience was tolerable; the suppressive effects of DCP on his bone marrow were not clinically significant.

Our in vitro molecular mechanism studies of DCPinduced signaling pathways of DNA damage-repair and apoptosis in human ovarian and prostate normal and cancer cells suggested that DCP mainly affects tumor cells, but not normal cells. However, we noticed that $\mathrm{p}$-Chk1, a marker of apoptosis, was activated by DCP in both normal and cancer cells, which suggests the need for further studies.

Our in vivo comparative assessment of DCP, cisplatin and carboplatin is consistent with the clinical data for - and the observations of - the first American cancer patient to receive DCP chemotherapy. The in vivo data revealed less damage

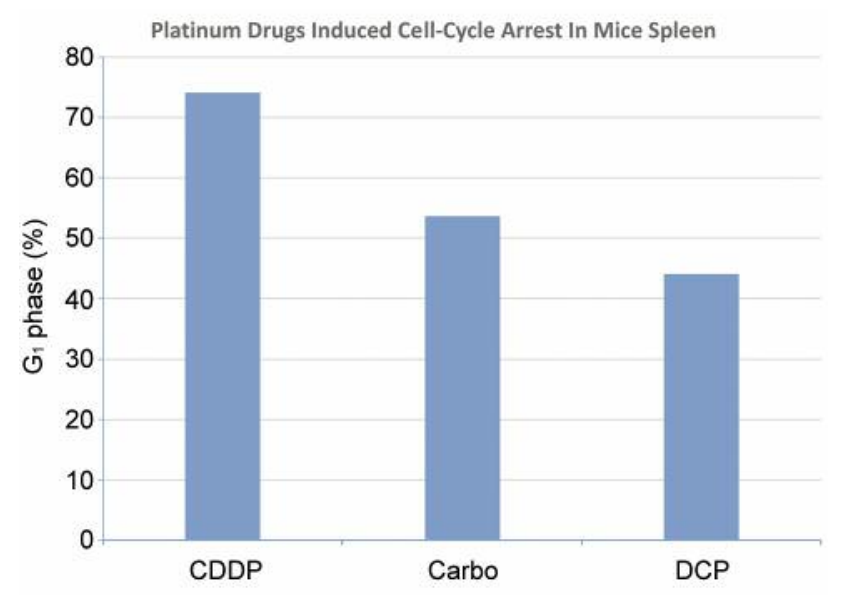

Figure 6. Cisplatin, carboplatin and DCP induced cell cycle arrest in mice spleen. Mice were intraperitoneally injected for 7 days with cisplatin, carboplatin (Carbo) and dicycloplatin at $1 / 2 L_{50}$ doses. Flow cytometry analysis was carried out to evaluate the effects of the three platinum drugs on cell cycle arrest in the $G_{1}$ phase of spleen.

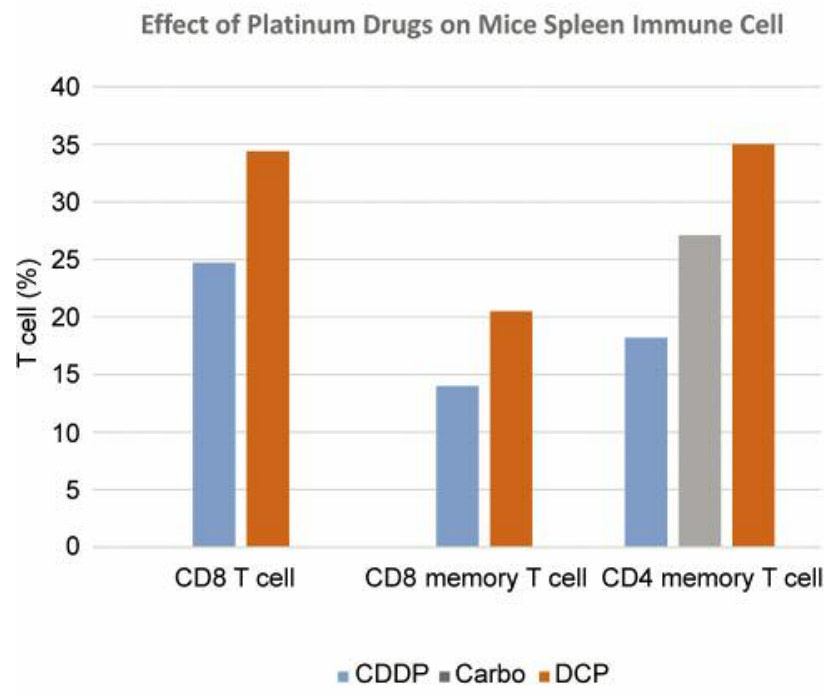

Figure 7. Effects of cisplatin, carboplatin and DCP on mouse spleen immune cells. Mice were intraperitoneally injected for 7 days with cisplatin, carboplatin or DCP at 1/2 LD $D_{50}$ doses. Eight-color flow cytometry evaluation of the immune status of spleen was performed to evaluate CD8 $T$ cells, CD8 memory $T$ cells and CD4 memory $T$ cells of mice spleen.

to mice by DCP compared to cisplatin and carboplatin, which may explain why the American patient did not experience serious side effects during DCP treatment. This is an important therapeutic advance in cancer chemotherapy.

In conclusion, our clinical and in vitro and in vivo laboratory assessments indicated that DCP is an effective and safe agent in cancer chemotherapy with less aggressive and more 
tolerable side effects than those typically associated with cisplatin and carboplatin. DCP appears to be a promising chemotherapeutic drug and may offer important therapeutic advantages over other platinum drugs. Clinical investigation of DCP as an alternative to cisplatin or carboplatin is warranted.

\section{Conflicts of Interest}

The Authors declare that they have no competing interests.

\section{Authors' Contributions}

Conception and design: Jing Jie Yu, Ida M Washington, Xiaobing Liang, Xuqing Yang; Patient care: Chad Morley, Chad Crigger, Shunchang Jiao, Dorian J. Williams, Mohamad W. Salkini, Jing Jie Yu; Animal care: Courtney Cecil, Ida M Washington; Data collection and assembly: Clinical data: Thomas Hogan, Jing Jie Yu, Yi Guo, Laboratory data: Xiaobing Liang, Bingxue Yan, Jenny Zheng, Ava C. Winn, Courtney Cecil; Data analysis and interpretation: Thomas Hogan, Yi Guo, Bing-Hua Jiang, Ava C. Winn, Xuqing Yang; Manuscript writing: All Authors. Final approval of manuscript: All Authors.

\section{Acknowledgements}

The Authors thank Michael D. Mueller for his special contributions to this research and for editorial assistance. The Authors also thank Ying Guo and Tao Zhang for graphics and other technical support. The Authors also thank DCP Project President Mr. Baoyu Qiu for his encouragement and support.

\section{References}

1 Lokich J and Anderson N: Carboplatin versus cisplatin in solid tumors: An analysis of the literature. Ann Oncol 9(1): 13-21, 1998. PMID: 9541678. DOI: 10.1023/a:1008215213739

2 National Comprehensive Cancer Network: NCCN Clinical Practice Guidelines in Oncology: Small cell lung cancerVersion v2.2012. http:// www.nccn.org.

3 du Bois A, Lück HJ, Meier W, Adams HP, Mobus V, Costa S, Bauknecht T, Richter B, Warm M, Schröder W, Olbricht S, Nitz U, Jackisch C, Emons G, Wagner U, Kuhn W and Pfisterer J: Arbeitsgemeinschaft Gynäkologische Onkologie Ovarian Cancer Study Group: A randomized clinical trial of cisplatin/paclitaxel versus carboplatin/paclitaxel as first-line treatment of ovarian cancer. J Natl Cancer Inst 95(17): 1320-1329, 2003. PMID: 12953086. DOI: $10.1093 /$ jnci/djg036

4 Ozols RF, Bundy BN, Greer BE, Fowler JM, Clarke-Pearson D, Burger RA, Mannel RS, DeGeest K, Hartenbach EM and Baergen R: Phase III trial of carboplatin and paclitaxel compared with cisplatin and paclitaxel in patients with optimally resected stage III ovarian cancer: A Gynecologic Oncology Group study. J Clin Oncol 21(17): 3194-3200, 2003. DOI: 10.1200/ JCO.2003.02.153
5 Rossi A, Di Maio M, Chiodini P, Rudd RM, Okamoto H, Skarlos DV, Früh M, Qian W, Tamura T, Samantas E, Shibata T, Perrone F, Gallo C, Gridelli C, Martelli O and Lee SM: Carboplatin- or cisplatin-based chemotherapy in first-line treatment of small-cell lung cancer: The COCIS meta-analysis of individual patient data. J Clin Oncol 30(14): 1692-1698, 2012. DOI: 10.1200/ JCO.2011.40.4905

6 Dasari S and Tchounwou PB: Cisplatin in cancer therapy: molecular mechanisms of action. Eur J Pharmacol 740: 364-378, 2014. DOI: 10.1016/j.ejphar.2014.07.025

7 Canetta R, Rozencweig M and Carter SK: Carboplatin: the clinical spectrum to date. Cancer Treat Rev 12(Suppl A): 125136, 1985. PMID: 3002623

8 Yang XQ, Yu JJ, Guo Y and Mueller MD: Dicycloplatin, a platinum - based supramolecule with 4 hydrogen bonds, is a promising chemotherapy drug. Frontiers in Clinical Drug Research - Anti-Cancer Agents. Volume 4. Sharjah, United Arab Emirates: Atta-ur-Rahman (Ed.) Bentham Science Publishers. pp. 339-362, 2017.

9 Yu JJ, Yang XQ, Song QH, Mueller MD and Remick SC: Dicycloplatin, a novel platinum analog in chemotherapy: Synthesis of Chinese preclinical and clinical profile and emerging mechanistic studies. Anticancer Res 34(1): 455-463, 2014. PMID: 24403501.

10 Yu JJ, Salkini MW, Jiao S, Hogan T, Guo Y, Liang XB, Yang B, Zhang L and Gyure K: The first American cancer patient to receive dicycloplatin chemotherapy: A case report. J Cancer Res Ther 5(9): 56-60, 2017.

11 Yu JJ, Jiao S, Salkini MW, Morley C, Williams DJ, Liang XB, Yan BX, Winn AC, Guo Y, Zheng J, Hogan T, Gyure K and Petros W: Seventeen-month report for first american cancer patient to receive dicycloplatin chemotherapy. Adv Inv Pha The Medic 1: 10-13, 2018.

12 Salkini MW, Morley C, Crigger C, Jiao S and Yu JJ: WV Resident is First American to Receive Dicycloplatin Chemotherapy: A WVU Urologic Oncology Case Report. Clinical Oncology and Research ISSN 2613-4942, 2018. Clinical Oncology \& Research DOI: 10.31487/j.COR.2018.02.005

13 Vantourout $\mathrm{P}$ and Hayday A: Six-of-the-best: unique contributions of $\gamma \delta \mathrm{T}$ cells to immunology. Nat Rev Immunol 13(2): 88-100, 2013. DOI: 10.1038/nri3384.

14 Gutcher I and Becher B: APC-derived cytokines and T cell polarization in autoimmune inflammation. J Clin Invest 117(5): 1119-1127, 2007. PMID: 17476341. DOI: 10.1172/JCI31720

15 Akbar AN, Terry L, Timms A, Beverley PC and Janossy G: Loss of CD45R and gain of UCHL1 reactivity is a feature of primed T cells. J Immunol 140(7): 2171-2178, 1988. PMID: 2965180.

Received June 17, 2019

Revised June 28, 2019

Accepted July 2, 2019 